\title{
Fertility and parenthood issues in young female cancer patients - a systematic review
}

\author{
Aleksandra Sobota ${ }^{\mathrm{a} 1}$ and Gozde Ozakinci ${ }^{\mathrm{a}}$
}

${ }^{\text {a }}$ School of Medicine, University of St Andrews, St Andrews, UK

University of St Andrews

School of Medicine

Biological and Medical Sciences Building

North Haugh

St Andrews, Fife

KY16 9TF

Scotland, UK

Email addresses and telephone numbers:

Aleksandra Sobota: as297@st-andrews.ac.uk

Gozde Ozakinci: go10@st-andrews.ac.uk,++(44) 1334463521

Funding:

Aleksandra Sobota's PhD is funded by the Danuta Richardson Medical Scholarship. This systematic review has not received any additional funding.

Conflict of interest:

The authors declare that they have no conflict of interest.

The final publication is available at Springer via http://dx.doi.org/10.1007/s11764-014-0388-9

${ }^{1}$ Corresponding author: Aleksandra Sobota. Email: as297@ @t-andrews.ac.uk 
Manuscript Journal of Cancer Survivorship

The final publication is available at Springer via http://dx.doi.org/10.1007/s11764-014-0388-9

\section{Abstract}

Purpose: For young women who were diagnosed with cancer prior to having children, reproductive potential might affect quality of life (QoL). This systematic review looks at fertility issues in young female cancer patients, focusing on their influence on psychological well-being, specific fertility-related interventions and reproductive decisions.

Methods: Thirteen medical and social science databases were searched for relevant articles up to December 2012, according to PRISMA guidelines. Twenty-six articles meeting the eligibility criteria were included in the review, along with 5 additional papers that missed the inclusion criteria narrowly. Narrative synthesis was used to analyse the studies.

Results: Depression, anxiety, and QoL seemed to be related to the perceptions of reproductive issues rather than to the fertility status based on the type of treatment received. Fertility-related interventions improved patients' QoL, decisional regret, and decisional conflict. Finally, cancer influenced women's reproductive decisions. Pursuing pregnancy was affected mainly by worries about child's and mother's health. Decisions about treatment were influenced by the wish to preserve fertility. The generalisability of these results might be undermined by small sample sizes and homogeneity of participants within and across the studies. Inferences about causality of associations are problematic due to predominantly crosssectional design.

Implications for cancer survivors: The existing literature gives preliminary insight into the importance of fertility for young women diagnosed with cancer. However, more research is needed in order to offer patients comprehensive care.

Keywords: cancer; fertility; parenthood; women; review; decision 
Manuscript Journal of Cancer Survivorship

The final publication is available at Springer via http://dx.doi.org/10.1007/s11764-014-0388-9

\section{Introduction}

The development of screening programmes and progress in cancer treatment have led to significant increase in cancer survival rates [1]. Given the comprehensive cancer treatment regimens involved, improving cancer patients' quality of life is an important challenge for clinicians. Evidence shows that for young women with a diagnosis of cancer, being able to build a family and have children may be an important and cherished life goal determining their quality of life after the end of treatment $[2,3]$. The qualitative evidence also suggests that being able to have children gives these women back their sense of normality, reconnects them with peers, and gives them additional motivation to survive the cancer diagnosis and treatment [2-6]. Since the age at first birth tends to increase [7], some women are diagnosed with cancer before they have had enough time to complete their families. Unsurprisingly, many of them step into the survivorship phase that is shadowed by reproductive concerns which can arise due to treatment resulting in sterility or the uncertainty regarding fertility status.

Treatment modalities for the most commonly diagnosed cancers (breast, cervical, and ovarian) but also other, less frequent malignancies are known to influence women's reproductive potential. For instance, the first line treatment for most of gynecological cancers but also other types of cancers located in the lower pelvis is surgery during which, depending on the stage of the disease, part or all of the reproductive organs are removed. This can lead to inability to bear biological children if hysterectomy or bilateral oophorectomy is performed. Total body irradiation (TBI) and pelvic irradiation may result in ovarian failure and damage to the uterine musculature and vascular system. Cranial irradiation can alter the functioning of hypothalamic-pituitary-gonadal axis resulting in reduced serum levels of sex-steroids and hence amenorrhea [8]. The negative effect of systemic chemotherapy (a standard treatment for young women with breast cancer) on reproductive function is widely acknowledged and depends on the age of the patient at drug administration, drug dosage, duration of therapy, and type of medications used $[8,9]$. Chemotherapy is known to diminish the ovarian reserve which may result in an early-onset menopause even in women who continue menstruating after having received systemic treatment [10]. Hormonal therapy employed in hormone-positive breast cancer has been shown to increase the risk of amenorrhea in cancer survivors [11]. Moreover tamoxifen, the most commonly prescribed drug is considered to be a teratogen, meaning that pregnancy should be contraindicated during the time of therapy [12, 13]. According to the guidelines, tamoxifen should be continued for five years after diagnosis [14]; therefore, for some patients with an already reduced ovarian reserve due to adjuvant chemotherapy, a window for childbearing would be very short. 
Manuscript Journal of Cancer Survivorship

The final publication is available at Springer via http://dx.doi.org/10.1007/s11764-014-0388-9

In 2006, for the first time, the American Society of Clinical Oncology issued guidelines concerning fertility preservation in young people affected by cancer [15]. These, as well as the reviewed version of the guidelines [16] recommend that all clinicians discuss the possibility that cancer treatment may result in infertility at the earliest opportunity with all the patients. For patients interested in looking into their fertility options, early referral to a fertility specialist is advised. Specific recommendations for procedures available for children, adult males and adult females were added to the reviewed version of the guidelines [16]. However, not all patients can undergo these recommended procedures. Some women might be ineligible for a conservative gynaecologic surgery due to the advanced stage of disease at diagnosis and others might feel overwhelmed having to make a fertility preservation decision in a very short time between cancer diagnosis and the onset of treatment [17].

Additionally, some women may fear cancer recurrence due to fertility preservation [18] or may not have the financial resources to afford it. Finally, some young patients do not recall having had a conversation about the impact of cancer treatment on fertility with their treating physicians $[19,20]$ which prevents them from making an informed decision about their fertility.

Even though discussing the effects that treatment might have on reproductive potential is a sensitive topic, the evidence shows that young women with cancer want information concerning fertility issues. According to Thewes et al. [13] women with breast cancer considered the provision of fertility-related information to be important at three time points: the time of diagnosis, treatment decision-making, and posttreatment follow-up. In a web-based survey by Partridge et al. [21], 57\% of breast cancer patients identified fertility concerns as a major issue at the time of their diagnosis. Qualitative data also indicate that some women are willing to alter the course of their cancer treatment [6] or forgo some part of treatment in order to preserve fertility [22].

Fertility is an important concern for young female cancer patients and several reviews tackling different aspects of this issue have been published over the last few years [23-27]. These articles contribute to our understanding of what fertility and parenthood mean to cancer patients [24] and how its meaning can change over cancer trajectory [23]. They also examine knowledge [25] and information needs of patients [27] and when it is appropriate to discuss fertility [25]. The majority, however, [23, 24, 26, 27], only concentrate on breast cancer patients and although breast cancer is the most frequently diagnosed cancer in younger women, other cancers also occur in this group of patients and their treatment can equally affect patients' fertility. One paper that describes how fertility issues are related to the quality of life [26] is not specific to cancer population and 
Manuscript Journal of Cancer Survivorship

The final publication is available at Springer via http://dx.doi.org/10.1007/s11764-014-0388-9

includes women with all types of non-communicable health conditions (e. g. cystic fibrosis, diabetes, epilepsy, PCOS). Although these different diseases can all affect fertility, the psychological burden might be different for a life-threatening disease such as cancer as compared to the other conditions included in the review. Finally, Goncalves et al. [24] discuss reproductive decisions in breast cancer patients only, focusing on survivors' attitudes and decisions towards pregnancy as well as risks and benefits of becoming a parent after cancer. Yet, this review did not include fertility preservation which constitutes one of the reproductive decisions that patients with cancer increasingly face.

Therefore, in this review we will address the gaps still present in the literature. First of all, we will delineate a relationship between fertility issues and psychological well-being of reproductive age women diagnosed with cancer while making a distinction between their objective fertility status and their subjective perception of reproductive concerns (Objective 1). We will also address the impact of fertility-specific interventions on young female cancer patients' psychological well-being (Objective 2). Finally, we will summarise the evidence on how cancer may affect reproductive decisions in young women with cancer, extending the definition of reproductive decisions beyond pregnancy post-cancer to treatment-related decisions that may affect fertility and also fertility preservation (Objective 3). This review will concentrate on all types of cancer diagnosed in women the treatment of which can potentially affect fertility.

For the purpose of this review, several terms needed clarification. Cancer treatment-related fertility issues were defined as both objective (e.g., surgery involving reproductive organs or chemotherapy) and subjective (e.g., self-assessed problems with conceiving or the reproductive concerns score as commonly measured by the Reproductive Concerns Scale [28]) as indicators of reproductive problems. Fertility-related interventions were operationalised as any type of intervention to promote fertility-related knowledge post-cancer diagnosis or provide psychosocial assistance (e.g., counselling by oncologists or fertility specialists, provision of decision aids and online support). Reproductive decisions were conceptualised as any decision that might relate to preserving the possibility of having children after cancer or actual decisions about childbearing post-cancer.

\section{Methods}

\section{Search strategy}

This systematic review was conducted according to the PRISMA guidelines (see Online Resource 1, Table 1). The search for relevant articles was performed using the following medical and social science search 
Manuscript Journal of Cancer Survivorship

The final publication is available at Springer via http://dx.doi.org/10.1007/s11764-014-0388-9

engines: NCBI (PubMed), OVID (Medline and Embase), Web of Science (Science Citation Index Expanded, Social Sciences Citation Index, Art\&Humanities Citation Index, Conference Proceedings Citation Index Science and Conference Proceedings Citation Index - Social Sciences \& Humanities), PROQUEST

(PsycArticles, Applied Social Sciences Index \& Abstracts) and COCHRANE (Cochrane systematic reviews, Cochrane controlled trials and Cochrane methodological register). All databases were searched up to December 2012 using the keywords presented in Table 2.

Table 1. Search terms

\begin{tabular}{|l|l|l|l|}
\hline Column 1 & Column 2 & Column 3 & Column 4 \\
\hline 'woman' & $\begin{array}{l}\text { 'cancer OR tumor } \\
\text { OR neoplasm OR } \\
\text { malignancy' }\end{array}$ & $\begin{array}{l}\text { 'fertility OR sterility } \\
\text { OR reproduction OR } \\
\text { childbearing OR } \\
\text { pregnancy' }\end{array}$ & $\begin{array}{l}\text { 'psychology OR distress OR depression OR } \\
\text { anxiety OR fear OR PTSD OR quality of life OR } \\
\text { self-esteem OR sexual OR recurrence OR } \\
\text { reproductive decision OR decision making OR } \\
\text { intervention OR counseling OR communication' }\end{array}$ \\
\hline
\end{tabular}

\section{Inclusion criteria}

\section{Population}

We included studies in which the study sample, at least in part, consisted of women diagnosed with various types of cancers (excluding childhood cancers and cancer diagnosed in the context of pregnancy) during their reproductive years. Being of reproductive age was defined as: (1) being premenopausal at the time of diagnosis or (2) being between 14 and 50 years of age at the time of diagnosis. The age range was selected based on the mean age at menarche and menopause worldwide [29]. If the study sample included women of all ages, it was eligible to be included only if the results for our target group were presented separately. In the case of studies including both men and women, only those presenting results separately for each gender and also our target age group were deemed eligible for inclusion. Studies that looked at women with various cancer diagnoses including cancers co-occurring with pregnancy or childhood cancers were only included if the results for our target group were presented separately.

Outcomes

Studies were included in the review if they measured the following outcomes for respective questions.

For Objective 1: Anxiety; Depression; Quality of life; Sexual functioning; Worries about future conception/pregnancy

For Objective 2: Anxiety; Depression; Quality of life; Decisional conflict; Decisional regret 
Manuscript Journal of Cancer Survivorship

The final publication is available at Springer via http://dx.doi.org/10.1007/s11764-014-0388-9

For Objective 3: No pre-specified outcomes were selected for this question due to diversity of possible significant outcomes

Study design

Quantitative experimental, quasi-experimental, and observational studies (cohort and case control studies) were included in the review.

\section{Exclusion criteria}

Studies were excluded if cancer diagnosis in the sample co-occurred with pregnancy (any cancer diagnosed in pregnant women or gestational trophoblastic disease); the focus of the study was on childhood cancers; combined results were presented for both genders, for women of all ages or for various cancers including childhood cancers and cancers diagnosed in the context of pregnancy. We also excluded papers that were written in non-English languages; the reviews, book chapters, commentaries, letters, guidelines, case studies and also the articles published before 1990, considering that the medical technology has changed substantially since then and new procedures allowing for the fertility sparing and preservation were established for female cancer patients [30]. Finally, we decided to exclude qualitative studies. We chose to do this since our search produced 44 qualitative articles potentially relevant based on title or abstract ( $8 \%$ of all the articles judged relevant by title) and these articles merit a separate qualitative synthesis, which was outside the scope of this review.

\section{Data collection and analysis}

A total number of 8040 articles were identified through the databases search. Automatic and manual de-duplication narrowed the number to 6507 articles. The first reviewer (AS) visually screened all the titles and identified 552 as potentially relevant. These 552 records were then examined by two reviewers as follows:

- The first reviewer extracted and read the abstracts of all the 552 articles; 56 of them were found to be potentially relevant.

- The second reviewer (GO) screened the titles of the 552 articles and singled out 385 that seemed potentially relevant. Subsequently the second reviewer read 385 abstracts and found 126 of them suitable. 
Manuscript Journal of Cancer Survivorship

The final publication is available at Springer via http://dx.doi.org/10.1007/s11764-014-0388-9

Both reviewers subsequently discussed the discrepancies between their choices and after excluding the abstracts that reported on medical outcomes only, did not mention fertility, or concentrated on childhood cancers, 81 articles were retained for full-text assessment. These articles were independently read in full by each reviewer and compared against the established inclusion and exclusion criteria. The first reviewer deemed 40 articles suitable while the second reviewer found 31 articles to match the criteria. The discrepancies were again resolved by discussion. The first reviewer contacted the authors of the publications that needed clarification in order to be included or excluded. We kept 26 articles meeting all the predefined criteria to be included in the review. The decision was also made to retain and separately describe five additional papers that missed one of the criteria (age or type of diagnosis) narrowly (see Online Resource 1, Figure 1). This is because excluding them could have potentially biased the results given that these studies have only slightly deviated from the inclusion criteria. Study by Carter et al. [31] included patients with gestational trophoblastic disease which was one of the exclusion criteria; however, they constituted only $6 \%$ of the study sample $(5 / 88)$ and thus were unlikely to significantly influence the results of the study. Similarly, in the studies that have not met the age criterion, the proportion of participants that were outside the predefined age brackets was minimal (6.4\% and $12.8 \%$ where it was possible to determine $[32,33]$ ) (for further details see Online Resource 2, Table 6).

In total, 31 papers describing 28 separate studies were included in the review (papers by Letourneau et al. [34] and Letourneau et al. [35]; Peate et al. [36] and Peate et al. [37]; and Carter et al. [38] and Carter et al. [39] referred to the same respective datasets). For details see Tables 3-6 in Online Resource 2.

The following data from the articles were extracted by the first reviewer: authors; date; location of study; study aim; study sample (including cancer type, age at diagnosis, sample size); study design; definitions of fertility; outcomes (constructs and measures); results for outcomes of interest.

Papers were also assessed for their quality using a checklist designed to examine and provide a quality score for quantitative studies employing various study designs [40]. The quality of 10 randomly selected articles was assessed by both reviewers. Where the discrepancies in scores occurred, they were discussed and the interrater reliability analysis was performed to determine the consistency between the observers. Kappa scores ranged from 0.44 to 1 representing moderate to substantial inter-rater agreement [41]. Subsequently, the first reviewer rated the quality of the remaining 21 articles. All the quality scores provided in the summary tables (see Tables 3-6 in Online Resource 2) are those assigned by the first reviewer. The narrative synthesis was used to analyse and interpret the data. The heterogeneity of study designs and outcome measures prevented the metaanalytic approach. 
Manuscript Journal of Cancer Survivorship

The final publication is available at Springer via http://dx.doi.org/10.1007/s11764-014-0388-9

\section{Results}

For the purpose of this review, the articles were organised according to the specific objective of the review they pertained to and further according to the outcomes they described. Since there were no predefined outcomes related to the third objective, studies falling into this category were classified in the following manner:

- The first group included articles that examined reproductive decisions related to pregnancy after cancer. Within this category, we concentrated on actual attempts to conceive, the desire to have children pre- and post-treatment as well as factors affecting decisions to have children after cancer. These results are summarised in the section titled "Pregnancy-related decisions".

- The second group comprised of the studies that explored decisions related to treatment modalities that could enable future fertility after cancer (fertility-sparing surgery or fertility preservation techniques). These results are summarised in the section titled "Treatment-related decisions".

\section{Impact of cancer treatment-related fertility issues in reproductive age women on their psychological well-being}

Worry about pregnancy

Three studies examined worries about pregnancy after cancer. These worries included the ability to become pregnant after treatment for breast cancer [42], the success of conceiving after radical trachelectomy [43], and concerns about conception after radical trachelectomy [38, 43]. In one study, $43.1 \%$ of breast cancer patients worried whether they would be able to have a pregnancy after cancer, if they wished that [42]. When asked about the success at conceiving, cervical cancer patients who underwent radical trachelectomy assessed their chance to be between $55 \%$ and $60 \%$ over a 2 -year follow-up post-surgery with no marked change during that time [43]. Concerns about conceiving in cervical cancer patients scheduled for fertility-sparing treatment ranged from $90 \%$ before treatment to $100 \%$ at six months post-surgery in one study [38] and from $88 \%$ at six months post-treatment to $73 \%$ at 24 months post-treatment in another study [43].

\section{Depression and anxiety}

Four studies looked at the association between fertility issues and depressive symptoms. One study used Hospital Anxiety and Depression Scale to measure depressive symptoms [44] while the remaining three 
Manuscript Journal of Cancer Survivorship

The final publication is available at Springer via http://dx.doi.org/10.1007/s11764-014-0388-9

used the Centre for Epidemiologic Studies-Depression scale [39, 45, 46]. The two studies that defined fertility issues using an objective measure of having undergone either fertility-sparing or radical treatment did not find significant difference in the level of depressive symptoms or anxiety between the two groups of patients (ovarian in Bisseling et al. [44] cervical in Carter et al. [39]). However, the latter study reported that the mean scores for depressive symptoms in both groups of patients, those who underwent radical trachelectomy as well as those treated with radical hysterectomy, were suggestive of depression before the onset of either treatment and remained in a subclinical range after treatment [39]. Another study by Carter et al. [45] examining the group of cervical cancer patients whose fertility was damaged due to treatment, reported that $40 \%$ of their sample met the criteria for depression as measured by CES-D. Finally Gorman et al. [46] examined the association between the amount of reproductive concerns and depressive symptoms in breast cancer patients and found a significant association between the two. However, we were not able to ascertain the strength of this relationship.

\section{Quality of life (QoL)}

Five studies assessed the relationship between fertility issues and QoL. Two of the studies used the Functional Assessment of Cancer Therapy scale (the Cervical or Trial Outcome Index version) [39, 47], the other two used the Medical Outcomes Scale SF-36 [48, 49], and one used the Medical Outcomes Scale SF-12 [50]. Two studies that operationalised fertility issues in a more objective manner (radical versus fertility-sparing treatment or occurrence of prolonged amenorrhea) did not find significant association between QoL and fertility issues. There was no significant difference in terms of QoL between patients who underwent radical trachelectomy and those who had radical hysterectomy [39]. Neither did prolonged amenorrhea at 12 month post-chemotherapy predict the quality of life in breast cancer patients [47]. The third study that referred to the medical definition of infertility (primary, where a woman did not have any children or secondary, where a woman had children prior to cancer and could not have them after treatment) post-cancer found a significant difference in the Mental Component Summary score (MCS) (SF-12) between women who had the desired children and those who were infertile [50]. Two studies in which fertility issues were defined in a more subjective manner (self-reported inability to have children post-cancer or the level of reproductive concerns as measured by RCS [28]) showed a significant association between QoL and fertility issues. In a study by Mancini et al. [48], cancer patients with various diagnoses who considered themselves infertile had significantly lower both Mental and Physical Component Summary (PCS) scores (SF-36) compared to participants who did not report infertility. Wenzel et al. [49] examined cervical cancer patients and although they found no 
Manuscript Journal of Cancer Survivorship

The final publication is available at Springer via http://dx.doi.org/10.1007/s11764-014-0388-9

differences in MCS and PCS between patients and healthy controls, better MCS scores among patients were significantly associated with fewer reproductive concerns. The latter were also significantly related to better survivor-specific QoL as measured by QoL-CS [49].

\section{Sexual functioning}

Four studies reported on the relationship between fertility issues and sexual functioning. To assess sexual functioning, two of the studies used the Female Sexual Functioning Index (FSFI) [39, 50], one study used the Gynecologic Problems Checklist (GCP) as well as the Sexual Activity Questionnaire (SAQ) [49], and lastly one study used a single question assessing sexual functioning [48]. Carter et al. [39] who compared cancer patients who had undergone fertility-sparing surgery for cervical cancer to those who had had radical treatment found no differences between the groups in terms of sexual functioning. However, both groups scored in the range of sexual dysfunction with the scores stable over the 24-month follow-up period. The study by Wenzel et al. [49] where two instruments were used to assess sexual functioning delivered mixed results indicating no difference between infertile cancer patients and controls in sexual functioning as measured by GCP but a significant difference in sexual discomfort as measure by SAQ. In Canada, Schover [50] study, patients with primary or secondary infertility post-cancer scored significantly lower on FSFI than women who had the desired children. In the same study, women who viewed themselves as infertile had lower sexual satisfaction that those who did not. Wenzel et al. [49] also indicated that higher reproductive concerns in survivors were significantly associated with poorer sexual functioning. Finally, Mancini et al. [48] found that patients who self-identified as infertile reported significantly more negative consequences of cancer and its treatment on sexual life that those patients who considered themselves fertile.

\section{Effect of fertility-related interventions delivered prior to cancer treatment on women's psychological well-being}

Quality of life (QoL)

Three studies explored the influence of fertility-related interventions for young female cancer survivors on their QoL $[34,51,52]$. Each study used a different QoL measurement tool which makes direct comparisons problematic. Letourneau et al. [34] compared young women diagnosed with various cancers who had been counselled about the possible impact of cancer treatment on their fertility to those who had not been counselled. 
Manuscript Journal of Cancer Survivorship

The final publication is available at Springer via http://dx.doi.org/10.1007/s11764-014-0388-9

Women who remembered being counselled had statistically significantly better physical and psychological health scores as measured by WHOQOL-BREF questionnaire [53] than their non-counselled counterparts. The QoL as measured by Satisfaction With Life Scale (SWLS) [54] did not differ between the groups. Similarly, in the models predicting QoL outcomes, adjusted for age at diagnosis, parity before treatment and cancer site, counselling (as primary predictor) did not reach statistical significance. Letourneau et al. [34] also examined different types of counselling and compared (1) women who had only been counselled by an oncologist to those who had been counselled by both an oncologist and fertility specialist and (2) women who had only been counselled by an oncologist to those who had been counselled by an oncologist and additionally pursued fertility preservation (FP). In the first case, women who had been counselled by both an oncologist and a fertility specialist had significantly better QoL as measured by SWLS and also fared better in the physical health domain of WHOQOL-BREF compared to women who had only been counselled by an oncologist. Counselling by both specialists remained a significant predictor of physical health in a model adjusted as above. A similar pattern was found when comparing women who had been counselled by an oncologist and who decided to pursue FP to those who had only been counselled by an oncologist. In an adjusted model, however, counselling and pursuing FP significantly predicted QoL as measured by SWLS [34].

A study by Meneses et al. [51] studied the effect on an online intervention consisting of educational resources and the possibility to interact with other survivors and the researchers on the QoL of young breast cancer survivors. They noted statistically significant improvements in all the QoL domains (as measured by SF36 [55]) between baseline and follow-up at six months.

Finally, Reh et al. [52] showed that among young cancer patients with various diagnoses referred to a fertility clinic, social domain of QoL as measured by FACT [56] improved over time in those who had undergone FP procedures, with other QoL scores remaining stable over time.

\section{Decisional regret}

Decisional regret was an outcome in two studies $[34,37]$. Both used the Decision Regret Scale as a measurement tool [57] and referred to either a "decision to undergo (or not undergo) fertility preservation" [34] or "fertility treatment decisions" [37]. Letourneau et al. [34] found that decisional regret was significantly lower in cancer survivors who had undergone counselling by both an oncologist and a fertility specialist compared to those counselled only by an oncologist. The same pattern was found for women who had been counselled by an oncologist and decided to pursue FP when compared to those who had only been counselled by an oncologist. In 
Manuscript Journal of Cancer Survivorship

The final publication is available at Springer via http://dx.doi.org/10.1007/s11764-014-0388-9

the models adjusted for age at diagnosis, parity before treatment and cancer site, counselling by oncologist and fertility specialist as well as counselling by oncologist and pursuing FP remained significant predictors of decisional regret. Peate et al. [37] studied the effect of a fertility-related decision aid (DA) compared to the usual care in breast cancer patients. They showed that women who received the DA did not significantly differ in decisional regret from women in the usual care at 1-month follow-up. The difference, however, reached significance at 12-month follow-up with women in the DA group having lower decisional regret.

\section{Decisional conflict}

Decisional conflict was measured as an outcome in one study using the Decisional Conflict Scale [37]. Young breast cancer survivors who received the DA experienced a greater reduction of the decisional conflict over 12 months than the patients in the usual care. The difference in the scores was not significant at 1-month follow-up but reached statistical significance at 12 months with the scores in the DA group 15.3 units lower on average than the scores in the usual care group.

Depression and anxiety

Peate et al. [37] also included depression and anxiety as outcomes in their study of the effect of the DA in a group of breast cancer patients. They found no significant differences in the change of either anxiety or depression as measured by HADS between the DA group and the usual care group over time.

\section{Impact of cancer diagnosis (from patient's perspective) on reproductive decisions in reproductive age} women and the possible psychological factors that might facilitate or hinder these decisions

Pregnancy-related decisions

Three studies looked at attempts to conceive post-cancer. In a study by Carter et al. [43] the number of cervical cancer survivors who had been treated with radical trachelectomy and who were trying to conceive post-treatment increased from $6 \%$ at 12 -month follow-up to $21 \%$ at 24 -month follow-up. Among breast-cancer survivors in a study conducted by Gorman et al. [46], 7\% reported trying to become pregnant after cancer. Among ovarian cancer patients treated with conservative surgery, $49 \%$ attempted to conceive after treatment and out of these, $75 \%$ were successful [58]. 
Manuscript Journal of Cancer Survivorship

The final publication is available at Springer via http://dx.doi.org/10.1007/s11764-014-0388-9

Eight studies explored the potential impact of cancer on the desire to have children. Huyghe et al. [59] and Gorman et al. [46] asked participants to rate their desire to have children pre- and post-diagnosis. In both studies, the numbers decreased from $43 \%$ to $29 \%$ and from $48 \%$ to $28 \%$, respectively. Braun et al. [60] compared breast cancer survivors to healthy controls and found that the former desired significantly fewer children than the latter. Canada, Schover [50] and Zanagnolo et al. [58] assessed how cancer affected the desire to have children in a mixed cancer group and ovarian cancer patients, respectively. According to Canada, Schover [50] the desire to have children remained unchanged in $68 \%$ of patients, $17 \%$ reported that cancer decreased their desire to have children whereas $15 \%$ described the opposite trend. A similar tendency was reported by Zanagnolo et al. [58] with $78 \%$ of patients reporting that cancer had no impact on their desire to have children, and 7\% and 5\% respectively declaring a decrease and increase in their desire for children.

Mancini et al. [48] and Patel et al. [61] only evaluated the desire to have children post-diagnosis and showed that $26.3 \%$ and $45 \%$ of participants wanted children after cancer, respectively. Finally, in a study by Atkinson et al. [62], 53.6\% of reproductive age melanoma survivors thought that cancer would make them better parents.

Eight studies examined potential factors affecting decisions related to pursuing pregnancy after cancer. A study by Braun et al. [60] showed that reported pros and cons of having children did not differ between breast cancer survivors and healthy controls; however, the remaining literature points to several factors influencing pregnancy-related decisions, specific for cancer survivors. These factors could generally be assigned to four categories: 1) child's health and well-being; 2) fear of cancer recurrence; 3) pregnancy complications; 4) mother's mental well-being.

Child's health and well-being

Across studies, participants were concerned about possible birth defects or malformations due to cancer (3.6\% of melanoma survivors in Atkinson et al. [62] and 15\% of ovarian cancer patients in Zanagnolo et al. [58]) or its treatment (24\% of participants in Zanagnolo et al. [58]), the risk of a child developing cancer (51.7\% of melanoma survivors in Atkinson et al. [62]) and prematurely bereaving a child (6.7\% of breast cancer survivors in a study by Rippy et al. [63]). Canada, Schover [50] also found that women who felt that cancer had interrupted their childbearing plans were more fearful of the effects that cancer could have on child's health.

Fear of cancer recurrence (FoR) 
Manuscript Journal of Cancer Survivorship

The final publication is available at Springer via http://dx.doi.org/10.1007/s11764-014-0388-9

Fear of cancer recurrence as an explicit category was found to affect survivors' decisions about pregnancy in three studies. It influenced reproductive decisions in $12.9 \%$ to $29 \%$ of patients ([62-64]. Avis et al. [42] reported that $48.3 \%$ of patients who were concerned about their fertility feared that pregnancy could affect the course of their disease. Additionally, Canada, Schover [50] found that women who felt that cancer had interfered with their childbearing plans were more worried that pregnancy could trigger cancer recurrence.

Pregnancy complications

Only Atkinson et al. [62] looked at concerns related to pregnancy complications due to cancer. In their sample of reproductive age melanoma survivors, $11.1 \%$ were bothered by the possibility that cancer might cause complications during pregnancy.

Mother's mental well-being

Finally, one study studied how mental health could affect pregnancy rates post-breast cancer [65]. A trend towards better mental health $(\mathrm{p}=0.08)$ was reported for women who became mothers after diagnosis and treatment compared to survivors who did not have children after cancer.

\section{Treatment-related decisions}

Five studies looked at treatment-related decisions that could impact on survivors' future childbearing. Two studies explored the decisions concerning fertility preservation [35, 36]. Among the three remaining studies each concentrated on a different treatment-related decision such as: the decision to undergo trachelectomy for cervical cancer [38, 39], the decision to undergo chemotherapy for breast cancer [21], and finally one study did not specify the type of treatment received by the participants [64].

Fertility concerns affected the decision about treatment in $29 \%$ of breast cancer survivors [21] and in $13 \%$ of mixed female cancer group [64]. This was more of a case in women who wanted children, had prior difficulty conceiving, and recalled severe depression prior to diagnosis [21] as well as younger, unmarried women who had no successful pregnancies prior to cancer [64]. Additionally, Partridge et al. [21] analysed the kind of risks and benefits women were willing to accept given that chemotherapy could impair their fertility. Women who were more concerned about their reproductive potential required greater recurrence risk reduction and were less likely to accept higher risk of infertility due to chemotherapy compared to their less concerned counterparts. 
Manuscript Journal of Cancer Survivorship

The final publication is available at Springer via http://dx.doi.org/10.1007/s11764-014-0388-9

Two publications from the same dataset by Carter et al. [38] and Carter et al. [39] examined patients' reasons to undergo radical trachelectomy (RT). The most frequently cited reason was preservation of childbearing (97\% of participants in the preliminary report [38] and 55\% of participants in the final report [39]), followed by conversations with doctors (41\% and 36\% in the preliminary [38] and full report [39] respectively), family or future fertility options $(41 \%,[38])$, personal factors $(28 \%,[38])$ and research (17\%, [39]). The full report [39] additionally examined the reasons for undergoing radical hysterectomy (RH) and found that $46 \%$ of patients decided upon this type of treatment following doctor's recommendations, $25 \%$ because of concerns about survival and another $25 \%$ because they felt it was the best or the only available option. A significant difference between the RT and RH groups emerged, showing that $43 \%$ of patients in the RH group versus only $7 \%$ of patients in the RT group had enough time to complete their families.

Letourneau et al. [35] and Peate et al. [36] concentrated on fertility preservation among cancer survivors. The former study reported several factors associated with pursuing FP procedures, mainly: the age at diagnosis, desire for future children, the number of children at diagnosis, and education level. The latter study found that the intention to undergo FP was related to the importance women attached to fertility information and attitudes towards FP [36]. Additionally, women who had better knowledge about fertility issues related to cancer presented significantly lower decisional conflict concerning FP (less delay in making decision and less uncertainty about the implementation of the choice) than women who had less knowledge about the topic [36].

\section{Additional articles}

Among the five articles that has just missed one of the inclusion criteria (age or type of diagnosis), two were related to the first objective of the review [31, 66], whereas 3 were related to the third objective [32, 33, 67]. In general, the results from these studies were in line with the results from the studies that met all the inclusion criteria.

The studies by Gershenson et al. [66] and Carter et al. [31] examined the impact of fertility issues on sexual functioning and depressive symptoms, respectively. Gershenson et al. [66] compared ovarian cancer patients who had undergone fertility sparing surgery to those who had had radical surgery and found that the latter group had a significantly greater sexual discomfort. Carter et al. [31] examined how distress caused by infertility secondary to cancer was associated with depressive symptoms in a sample of gynaecological cancer patients. They found that higher levels of distress were strongly related to depression as measured by CES-D. 
Manuscript Journal of Cancer Survivorship

The final publication is available at Springer via http://dx.doi.org/10.1007/s11764-014-0388-9

Studies related to the third objective of this review all explored pregnancy-related decisions. In a study of a breast cancer population, Ganz et al. [32] found that $7 \%$ were attempting to conceive and $17 \%$ did manage to get pregnant post-cancer. Similarly, $18 \%$ of women reported getting pregnant post-diagnosis in a study of a mixed cancer population [67]. Ganz et al. [32] reported that the desire for children diminished, with $20 \%$ of women wanting children pre-diagnosis and only $11 \%$ post-diagnosis. However, in a study by Schover et al. [67], $47 \%$ of women wanted pregnancy in the future. Sait [33] reported that $44 \%$ of the ovarian cancer participants claimed that cancer had not changed their desire to have children. Finally, the factors that could affect the decisions about pregnancy were child's or mother's health. $61 \%$ of ovarian cancer patients worried about the possible impact of their disease and treatment on offspring and $15 \%$ were anxious about complications or malformations in children [33].Risk of cancer recurrence and worry about pregnancy complications were mentioned by $17 \%$ and $13 \%$ of participants respectively in a study by [67].

\section{Discussion}

The aim of the current review was to investigate fertility and parenthood issues experienced by young female cancer survivors.

The first objective of this review was to synthesise the evidence for the impact of cancer treatmentrelated fertility issues in reproductive age women on their psychological well-being. The findings suggest that fertility issues related to cancer treatment can indeed affect women's psychological well-being; however, this depends both on the outcome of interest and also the definitions of fertility issues across the studies.

Worries about pregnancy were present in both breast and cervical cancer survivors [38, 42, 43]. In the group of breast cancer patients this may be due to uncertainty about fertility status after chemotherapy since it is known to diminish fertility. Its effect depends on multiple factors (type of regimen, dose, and age of the patient) $[8,9]$ and even though methods exist to assess ovarian reserve in patients (and by proxy their fertility potential) these are not systematically used [8]. Therefore, patients cannot be sure about their reproductive potential, unless they get pregnant. Patients with cervical cancer treated with fertility sparing surgery might still worry about future pregnancy since this procedure is known to cause cervical stenosis (the narrowing of the cervical canal), scarring, and changes to the normal anatomy of the cervix which can all lead to infertility [68]. It can also result in pregnancy complications such as pregnancy loss or premature delivery [68, 69].

There was some evidence that depressive symptoms were present among gynaecological cancer patients $[39,45]$ but they did not seem to differ by treatment modality (fertility sparing versus radical surgery) 
Manuscript Journal of Cancer Survivorship

The final publication is available at Springer via http://dx.doi.org/10.1007/s11764-014-0388-9

$[39,44]$. However, self-reported distress or concerns related to fertility issues were associated with more depressive symptoms $[31,46]$. A similar pattern emerged from the studies looking at QoL as an outcome. Where fertility issues were conceptualised objectively - as prolonged amenorrhea or radical treatment, they did not correlate with QoL $[39,47]$. However, where self-report measures assessing reproductive potential were used, fertility issues were significantly related to QoL [48-50]. Holton et al. [25] systematic review of childbearing concerns and information needs of women with chronic non-communicable health conditions suggests that reproductive issues can influence the quality of life and add to depressive symptoms in this group of women, yet they do not make a distinction between the subjectively and objectively defined fertility issues.

Studies examining sexual functioning delivered mixed results which depended to some extent on the measurement tool used [49]. Yet, similar to the findings on depressive symptoms and QoL, sexual functioning tended to be associated more with self-reported level of fertility concerns [48-50] than objectively defined infertility [39]. Nonetheless, patients, despite the treatment they had received, reported impaired sexual functioning [39].

These results may suggest that depressive mood and QoL of young women who were treated for cancer do not seem to be related to their objective fertility status but rather to the perception they have of their reproductive potential. This is in line with Leventhal's Common Sense Model of Illness [70, 71] which suggests that it is not the objective characteristics of a particular illness but the way individuals conceptualise them that may affect the way they psychologically respond to illness. One of the concepts studied within the context of psycho-oncology, fear of cancer recurrence, showed a similar pattern. According to a recent review by Simard et al. [72], these fears do not seem to be associated with the objective characteristics of the disease such as cancer type, stage or treatment but rather with physical symptoms and various psychological factors.

Since objectively defined fertility status does not seem to be related to psychological well-being as even women who underwent fertility sparing procedures present with psychological issues, fertility-related interventions may play an important role in comprehensive cancer care for young women. The second objective of this review was to look at such interventions and their influence on women's psychological well-being. The scarce evidence from the literature points to beneficial effect of fertility-related interventions. Outcomes specifically related to decision making such as decisional regret and decisional conflict improved when patients were provided with the decision aid or counselled by a fertility specialist [34, 37]. Particularly for decision aids, evidence shows that they reduce decisional conflict related to the feelings of being uninformed or unsure about personal values that may affect the decision [73]. They also stimulate patients to be more active in their 
Manuscript Journal of Cancer Survivorship

The final publication is available at Springer via http://dx.doi.org/10.1007/s11764-014-0388-9

treatment-related decision-making process [73]. Patients may not always be interested in independently deciding upon their treatment [74-76]; however, the literature shows that most of the time they want to be informed about their options [77-79]. This allows individuals to gain control over their life, promotes participation in treatment and increases compliance, reduces anxiety, and also creates realistic expectations about the future [80, 81]. Two systematic reviews targeting breast cancer survivors [26, 27] and one including women with variable chronic non-communicable diseases [25] explored their information needs concerning fertility and found that women wanted information about fertility; however only $34 \%$ to $72 \%$ across different studies reported having had a conversation about fertility with their physician. Especially women without children and those with a high desire for future children express the importance of fertility-related information since it might be a factor that plays a role in treatment decision-making [27].

Counselling, online support, and finally fertility preservation all seemed to have improved patients' quality of life. Online interventions might be a promising way of delivering support especially to younger cancer survivors. The World Wide Web is a fast growing resource to which particularly younger people turn to in order to find information concerning their health $[82,83]$. They also seek peer support via social media [84] or online forums [85]. Likewise, researchers have noticed the benefits of the Internet and a variety of interventions have been designed and delivered online for a range of cancer-related problems [86-90].

Out of all the medical options, fertility preservation treatment not only empowers young women with knowledge conveyed during fertility consultation but also offers a real possibility of having children after the cessation of cancer treatment. As suggested by the American Society of Clinical Oncology [15, 16] as well as National Institute for Health and Care Excellence guidelines [91], all cancer patients in their reproductive years should be counselled concerning the effect of cancer on fertility and where possible, offered FP treatment. This is important since the qualitative evidence shows that patients value childbearing opportunity post-cancer because it gives them the sense of normality, reconnects them with peers and motivates them to look forward to the future [2-6]. Nonetheless, there exist several barriers to discussing fertility with young patients $[18,20,92]$ which may in turn affect who gets referred to fertility specialists and undergoes FP.

The third objective of this review was to look at the reproductive decisions in young female cancer survivors. Two studies that looked at predictors of the uptake of FP treatment $[34,37]$ indicated that several factors exist associated with pursuing FP, including younger age, desire for children, not having children, level of education, and also attitudes towards FP. Whether some of these factors emerged because of the way clinicians selected patients who should be referred to FP or whether effectively younger and childless women 
Manuscript Journal of Cancer Survivorship

The final publication is available at Springer via http://dx.doi.org/10.1007/s11764-014-0388-9

are more likely to pursue FP remains unexplained. Some clinicians may be reluctant to refer their patients to FP treatment which results from their relative lack of knowledge and where to refer patients [20] as well as its relative novelty [93]. Nonetheless, other techniques can be used to spare fertility in cancer patients. Radical trachelectomy for cervical cancer is one of them. This is a choice for patients who were diagnosed with cancer in early stages. As the evidence suggests, young cervical cancer patients report a desire to preserve their fertility as a main reason to undergo this type of treatment $[39,38]$. Fertility also seemed to affect decisions concerning chemotherapy for breast cancer with women who wanted to preserve their childbearing potential being less likely to accept chemotherapy [21].

Surviving cancer diagnosis, avoiding cancer recurrence but also preserving one's reproductive potential, is challenging. Often these decisions are made under substantial uncertainty regarding the outcome (more radical treatment that could impair fertility does not necessarily prevent recurrence nor guarantee higher odds of survival in carefully selected groups of patients [94]). According to the prospect theory [95], which describes making decisions under risk and uncertainty, the value of an outcome of a decision is not absolute. This theory purports that in the editing stage of the decision-making process one sets a reference value and the potential outcomes are coded as losses or gains relative to the reference point. Subsequently, in the evaluation phase, the probability of each possible outcome is assessed and these probabilities are weighed against the values. The decision is finally made based on the outcomes' final utilities conceptualised as subjective values. Treadwell, Lenert [96] who applied the prospect theory to health values explain that changes in health states are relative to an individual baseline level of health. If this reference level, even in the context of cancer involves intact reproductive health and the subjective value attached to it is high, then a decision to undergo fertility sparing treatment might be a reasonable one. Similar reasoning might be applied to decisions about pregnancy after cancer treatment. If pregnancy and expanding one's family is highly valued, the decision to conceive might be made despite factors that appear in the literature such as worries about child's and mother's health or fear of cancer recurrence $[42,50,58,62-64]$. As mentioned earlier, pregnancy subsequent to cancer might be related to cancer survivors' well-being. Adams et al. [23] in their review of qualitative literature focusing on experiences of young breast cancer survivors suggest that being able to achieve a pregnancy after cancer is part of the normalising process which allows women to continue with their everyday lives after diagnosis. In another review exploring attitudes towards childbearing among breast cancer survivors, Goncalves et al. [24] also point to beneficial effects of having children after cancer such as regaining hope about the future, being motivated to stay healthy and alive, and reconnecting with peers. On the other hand, Adams et al. [23], Goncalves et al. [24] , 
Manuscript Journal of Cancer Survivorship

The final publication is available at Springer via http://dx.doi.org/10.1007/s11764-014-0388-9

and Peate et al. [27] underline that many women change their reproductive decisions and abandon their wish for children because of multiple fears they experience with regard to their own health and the health of future children. Yet, the medical literature suggests that pregnancy after breast does not increase mortality or the risk of cancer recurrence [97-99], nor does it result in foetal malformations [100,101]. This needs to be brought to patients' attention given that these are the most frequently mentioned factors that might influence decisions about conception post-cancer. As noted earlier, radical trachelectomy may indeed result in perinatal complications, however, with close obstetrical follow-up, a successful pregnancy is possible [69].

On the whole, the results related to the third objective suggest that cancer can have mixed effect on childbearing subsequent to cancer. For the majority of the patients, there was no change in their desire for children; however, the minority that reported the decrease in their desire for children should not be neglected. It is especially important for the latter group that information about risks associated with reproduction post-cancer should be clearly presented in order for them to be able to make informed decisions about their fertility.

\section{Limitations}

The above conclusions should be interpreted accounting for both the limitations of the included studies as well as those of the review.

In general, across all the included studies, several weaknesses have been identified. These include small sample sizes, homogeneity of participants within the studies and homogeneity of locations across the studies (with 21 studies having been conducted in the US, 2 in Australia and 1 in each of the following countries: France, Italy, United Kingdom, Israel and Saudi Arabia), predominantly cross sectional design, heterogeneity of outcome measures, and the lack of clear definition of fertility issues. The quality checklist [40] was used to assess the quality of each included study. The overall quality scores ranged from $44.4 \%$ to $100 \%$ ( $55.6 \%$ to $100 \%$ for studies related to objective $1 ; 68.2 \%$ to $90.9 \%$ for studies related to objective $2 ; 44.4 \%$ to $100 \%$ for studies related to objective 3 , and $61.6 \%$ to $90.9 \%$ for additional articles). The median quality scores for studies pertaining to objectives $1,2,3$ and for additional studies were $86.4 \%, 77 \%, 81.85 \%$ and $72.7 \%$ respectively. This suggests that on the whole the quality of the included studies was acceptable; however, caution should be applied especially when considering the conclusions related to objective 1.

Three studies pertaining to objective 1 that received the lowest scores: $55.6 \%, 60 \%$ and $66.7 \%$ [38, 43, 45] all looked at the psychological well-being of cervical cancer patients and presented descriptive statistics based on very small sample sizes (20-33 participants). All of them defined fertility issues as the provision of 
Manuscript Journal of Cancer Survivorship

The final publication is available at Springer via http://dx.doi.org/10.1007/s11764-014-0388-9

fertility sparing or compromising treatment. This might have introduced bias into our findings that when fertility issues are defined in an objective manner, they do not impact on well-being. However, four other studies of acceptable quality $(>80 \%)$ which also conceptualised fertility in objective terms, continue to support our conclusions.

Two of the above studies $[38,43]$ and two additional ones $[61,64]$ that scored $44.4 \%$ and $65 \%$ respectively, were included in the summary of the results for objective 3 . These results were to a certain extent balanced by the remaining 14 studies of satisfactory quality $(>70 \%)$ that pertained to objective 3 .

Although the quality of the studies related to objective 2 was generally good, the small number of studies $(\mathrm{n}=4)$ prevents from drawing firm conclusions.

The number of participants ranged from 20 to 1088 (median 71) across studies related to objective 1, from 29 to 1041 (median 106) across studies related to objective 2 and from 20 to 1088 (median 102) across studies related to objective 3. Given the large numbers of predictors and outcomes looked at in most of the studies, there exists a possibility they might have been underpowered to detect significant associations or changes in outcomes. Additionally, the vast majority of the studies did not provide the information about the estimated sample size needed to power the calculations. This might have biased the results of the individual studies and thus the conclusions of this review.

The samples in most of the studies consisted of well-educated, predominantly white women with relatively high income, which is an issue in this type of research in general. Also, the majority of the studies $(81.2 \%, 75 \%, 72.2 \%$ and $80 \%$ for objectives $1,2,3$ and additional studies, respectively) were conducted in the United States. This undermines the generalizability of the conclusions of this review, especially since the problems with fertility and attitudes towards parenting are strongly dependent on socio-cultural norms [102].

The majority of the studies pertaining to objectives 1 and 3 (63.6\% and 66.7\%, respectively) used cross-sectional design. This allows drawing conclusions about associations between fertility issues and wellbeing; however, makes the inferences about causality problematic. For objective 2, three studies were interventions while one used the exposure study methodology [34]. The latter had the biggest sample size $(n=918)$ and also looked at many outcomes of interest, which given the overall small number of studies, might have influenced the conclusions.

The heterogeneity of outcome measures made comparing the results of individual studies problematic, since different instruments, even when measuring the same constructs, might have been based on slightly different definitions of these constructs (e.g. the quality of life). 
Manuscript Journal of Cancer Survivorship

The final publication is available at Springer via http://dx.doi.org/10.1007/s11764-014-0388-9

Finally, the definitions of fertility issues differed between the studies. Even within the categories that were adopted for the purpose of this review (see Review objectives), the definitions were not homogenous. Some of the studies made the definition explicit, while others did not provide the definition at all [42]. This means that we cannot be sure if the results included in this review all tapped into the same construct of fertility issues.

Also, this review only looked at the published literature that was searched via electronic databases. This means that due to publication bias, we might have failed to include studies presenting insignificant results. The exclusion of the articles written in non-English languages might have additionally contributed to the omission of relevant papers and thus introduced bias. However, only $4 \%$ of all the articles judged as potentially relevant based on their title were published in a language other than English. Finally, we have not looked at how different healthcare systems across the countries where the studies have been conducted, could potentially influence our findings. Treatment-related decisions, especially pursuing FP can effectively be constrained in the countries where FP is not covered by the health insurance. The studies included in this review that examined the decisions about FP did not specifically investigate costs as a barrier to pursuing FP. In the study by Letourneau et al. [35], income was not related to pursuing fertility preservation, however more research explicitly analysing how costs can influence FP-related decisions is needed.

\section{Conclusions}

This review highlights the importance of fertility issues in a population of younger cancer survivors.

Overall the evidence suggests that:

- Perception of one's own reproductive potential might be more powerful in affecting women's psychological well-being than the objective fertility status.

- Empowering women with knowledge concerning their fertility after cancer seems to have beneficial effects on their QoL and decision-specific outcomes. Offering fertility preservation to young cancer patients is an important part of the comprehensive cancer care.

- Cancer can have mixed effect on reproductive decisions in young female cancer survivors. Factors that affected women's decisions encompassed mostly medical concerns about the offspring's and mother's health. Yet the evidence from the medical research does not seem to warrant such fears. 
Manuscript Journal of Cancer Survivorship

The final publication is available at Springer via http://dx.doi.org/10.1007/s11764-014-0388-9

The above conclusions should, however, be treated with caution due to multiple limitations of the studies included in the review as well as the limitations of the review itself.

\section{Funding}

Aleksandra Sobota's PhD is funded by the Danuta Richardson Medical Scholarship. This systematic review has not received any additional funding.

\section{Conflict of interest}

Aleksandra Sobota declares that she has no conflict of interest.

Gozde Ozakinci declares that she has no conflict of interest.

\section{Human and Animal Rights and Informed Consent}

No animal or human studies were carried out by the authors for this article.

\section{References}

1. Aziz NM, Rowland JH. Trends and advances in cancer survivorship research: challenge and opportunity. Semin Radiat Oncol. 2003; doi: 10.1016/S1053-4296(03)00024-9

2. Dow KH. Having children after breast cancer. Cancer Pract. 1994;2(6):407-13.

3. Siegel K, Gorey E, Gluhoski V. Pregnancy decision making among women previously treated for breast cancer. J Psychosoc Oncol. 1997; doi:10.1300/j077v15n01_03

4. Siegel K, Gluhoski V, Gorey E. Age-related distress among young women with breast cancer. J Psychosoc Oncol. 1999; doi:10.1300/J077v17n01_01

5. Connell S, Patterson C, Newman B. A qualitative analysis of reproductive issues raised by young Australian women. Health Care Women Int. 2006; doi:10.1080/07399330500377580

6. Yee S, Abrol K, McDonald M, Tonelli M, Liu KE. Addressing Oncofertility Needs: Views of Female Cancer Patients in Fertility Preservation. J Psychosoc Oncol. 2012; doi:10.1080/07347332.2012.664257.

7. Mean age of mothers at first childbirth. In: OECD Family Database. Organisation for Economic Co-operation and Development. 2012.

http://www.oecd.org/social/soc/SF2.3\%20Mean\%20age\%20of\%20mother\%20at\%20first\%20childbirth\%20\%20updated\%20240212.pdf. Accessed 3 Mar 2014. 
Manuscript Journal of Cancer Survivorship

The final publication is available at Springer via http://dx.doi.org/10.1007/s11764-014-0388-9

8. Wallace WH, Anderson RA, Irvine DS. Fertility preservation for young patients with cancer: who is at risk and what can be offered? Lancet Oncol. 2005; doi: 10.1016/S1470-2045(05)70092-9

9. Knobf MT. Reproductive and hormonal sequelae of chemotherapy in women. Premature menopause and impaired fertility can result, effects that are especially disturbing to young women. Am J Nurs. 2006;106(3 Suppl):60-5.

10. Duffy C, Allen S. Medical and psychosocial aspects of fertility after cancer. Cancer J. 2009; doi:10.1097/PPO.0b013e3181976602

11. Lee MC, Gray J, Han HS, Plosker S. Fertility and reproductive considerations in premenopausal patients with breast cancer. Cancer Control. 2010;17(3):162-72.

12. Barthelmes L, Gateley CA. Tamoxifen and pregnancy. The Breast. 2004; doi: 10.1016/j.breast.2004.08.007 13. Thewes B, Meiser B, Taylor A, Phillips KA, Pendlebury S, Capp A et al. Fertility- and menopause-related information needs of younger women with a diagnosis of early breast cancer. J Clin Oncol. 2005; doi:

10.1200/JCO.2005.07.773

14. Breast Cancer Treatment (PDQ®). National Cancer Institute. 2013.

http://www.cancer.gov/cancertopics/pdq/treatment/breast/healthprofessional/page6\#Section_95. Accessed 7 Feb 2013

15. Lee SJ, Schover LR, Partridge AH, Patrizio P, Wallace WH, Hagerty K et al. American Society of Clinical Oncology Recommendations on Fertility Preservation in Cancer Patients. J Clin Oncol. 2006; doi:10.1200/jco.2006.06.5888

16. Loren AW, Mangu PB, Beck LN, Brennan L, Magdalinski AJ, Partridge AH et al. Fertility preservation for patients with cancer: American Society of Clinical Oncology clinical practice guideline update. J Clin Oncol. 2013; doi:10.1200/jco.2013.49.2678

17. Klock SC, Zhang JX, Kazer RR. Fertility preservation for female cancer patients: early clinical experience. Fertil Steril. 2010; doi:10.1016/j.fertnstert.2009.03.028

18. Quinn GP, Vadaparampil S, Gwede C, Miree C, King LM, Clayton HB et al. Discussion of fertility preservation with newly diagnosed patients: oncologists’ views. J Cancer Surviv. 2007; doi:10.1007/s11764007-0019-9

19. Duffy C, Allen S, Clark M. Discussions Regarding Reproductive Health for Young Women With Breast Cancer Undergoing Chemotherapy. J Clin Oncol. 2005; doi:10.1200/jco.2005.01.134 
Manuscript Journal of Cancer Survivorship

The final publication is available at Springer via http://dx.doi.org/10.1007/s11764-014-0388-9

20. Quinn GP, Vadaparampil ST, Bell-Ellison BA, Gwede CK, Albrecht TL. Patient-physician communication barriers regarding fertility preservation among newly diagnosed cancer patients. Soc Sci Med. 2008; doi: 10.1016/j.socscimed.2007.09.013

21. Partridge AH, Gelber S, Peppercorn J, Sampson E, Knudsen K, Laufer M et al. Web-based survey of fertility issues in young women with breast cancer. J Clin Oncol. 2004; doi:10.1200/jco.2004.01.159

22. Partridge AH, Ruddy KJ. Fertility and adjuvant treatment in young women with breast cancer. The Breast. 2007; doi: 10.1016/j.breast.2007.07.029

23. Adams E, McCann L, Armes J, Richardson A, Stark D, Watson E et al. The experiences, needs and concerns of younger women with breast cancer: a meta-ethnography. Psychooncology. 2011; doi: 10.1002/pon.1792

24. Goncalves V, Sehovic I, Quinn G. Childbearing attitudes and decisions of young breast cancer survivors: a systematic review. Hum Reprod Update. 2014; doi: 10.1093/humupd/dmt039

25. Holton S, Kirkman M, Rowe H, Fisher J. The childbearing concerns and related information needs and preferences of women of reproductive age with a chronic, noncommunicable health condition: a systematic review. Womens Health Issues. 2012; doi: 10.1016/j.whi.2012.08.001

26. Howard-Anderson J, Ganz PA, Bower JE, Stanton AL. Quality of life, fertility concerns, and behavioral health outcomes in younger breast cancer survivors: a systematic review. J Natl Cancer Inst. 2012; doi:10.1093/jnci/djr541

27. Peate M, Meiser B, Hickey M, Friedlander M. The fertility-related concerns, needs and preferences of younger women with breast cancer: a systematic review. Breast Cancer Res Treat. 2009; doi: 10.1007/s10549009-0401-6

28. Wenzel L, Dogan-Ates A, Habbal R, Berkowitz R, Goldstein DP, Bernstein M et al. Defining and measuring reproductive concerns of female cancer survivors. J Natl Cancer Inst Monogr. 2005; doi:10.1093/jncimonographs/lgi017

29. Thomas F, Renaud F, Benefice E, De Meeus T, Guegan J-F. International variability of ages at menarche and menopause: patterns and main determinants. Hum Biol. 2001:271-90.

30. Dargent D, Brun JL, Roy M, Remy I. Pregnancies following radical tracheletcomy for invasive cervical cancer. Gynecol Oncol. 1994; doi: 10.1006/gyno.1994.1020

31. Carter J, Chi DS, Brown CL, Abu-Rustum NR, Sonoda Y, Aghajanian C et al. Cancer-related infertility in survivorship. Int J Gynecol Cancer. 2010; doi:10.1111/IGC.0b013e3181bf7d3f 
Manuscript Journal of Cancer Survivorship

The final publication is available at Springer via http://dx.doi.org/10.1007/s11764-014-0388-9

32. Ganz PA, Greendale GA, Petersen L, Kahn B, Bower JE. Breast cancer in younger women: reproductive and late health effects of. J Clin Oncol. 2003; doi:10.1200/jco.2003.04.196

33. Sait KH. Conservative treatment of ovarian cancer Safety, ovarian function preservation, reproductive ability, and emotional attitude of the patients in Saudi Arabia. Saudi Med J. 2011;32(9):913-8.

34. Letourneau JM, Ebbel EE, Katz PP, Katz A, Ai WZ, Chien AJ et al. Pretreatment fertility counseling and fertility preservation improve quality of life in reproductive age women with cancer. Cancer. 2012; doi:10.1002/cncr.26459

35. Letourneau JM, Smith JF, Ebbel EE, Craig A, Katz PP, Cedars MI et al. Racial, socioeconomic, and demographic disparities in access to fertility preservation in young women diagnosed with cancer. Cancer. 2012; doi:10.1002/cncr.26649

36. Peate M, Meiser B, Friedlander M, Zorbas H, Rovelli S, Sansom-Daly U et al. It's Now or Never: FertilityRelated Knowledge, Decision-Making Preferences, and Treatment Intentions in Young Women With Breast Cancer-An Australian Fertility Decision Aid Collaborative Group Study. J Clin Oncol. 2011; doi:10.1200/jco.2010.31.2462

37. Peate M, Meiser B, Cheah BC, Saunders C, Butow P, Thewes B et al. Making hard choices easier: a prospective, multicentre study to assess the efficacy of a fertility-related decision aid in young women with early-stage breast cancer. Br J Cancer. 2012; doi:10.1038/bjc.2012.61

38. Carter J, Sonoda Y, Abu-Rustum NR. Reproductive concerns of women treated with radical trachelectomy for cervical cancer. Gynecol Oncol. 2007; doi:10.1016/j.ygyno.2006.10.059

39. Carter J, Sonoda Y, Baser RE, Raviv L, Chi DS, Barakat RR et al. A 2-year prospective study assessing the emotional, sexual, and quality of life concerns of women undergoing radical trachelectomy versus radical hysterectomy for treatment of early-stage cervical cancer. Gynecol Oncol. 2010; doi:10.1016/j.ygyno.2010.07.016

40. Kmet L, Lee R, Cook L. Standard quality assessment criteria for evaluating primary research papers from a variety of fields. In: HTA Initiative 13. 2004. http://www.ihe.ca/documents/HTA-FR13.pdf. Accessed 7 Feb 2014.

41. Viera AJ, Garrett JM. Understanding interobserver agreement: the kappa statistic. Fam Med. 2005;37(5):360-3.

42. Avis NE, Crawford S, Manuel J. Psychosocial problems among younger women with breast cancer.

Psychooncology. 2004; doi:10.1002/pon.744 
Manuscript Journal of Cancer Survivorship

The final publication is available at Springer via http://dx.doi.org/10.1007/s11764-014-0388-9

43. Carter J, Raviv L, Sonoda Y, Chi DS, Abu-Rustum NR. Recovery Issues of Fertility-Preserving Surgery in Patients With Early-Stage Cervical Cancer and a Model for Survivorship The Physician Checklist. Int J Gynecol Cancer. 2011; doi:10.1097/IGC.0b013e3182017989

44. Bisseling K, Kondalsamy-Chennakesavan S, Bekkers RLM, Janda M, Obermair A. Depression, anxiety and body image after treatment for invasive stage one epithelial ovarian cancer. Aust N Z J Obstet Gynaecol. 2009; doi:10.1111/j.1479-828X.2009.01074.X

45. Carter J, Rowland K, Chi D, Brown C, Abu-Rustum N, Castiel M et al. Gynecologic cancer treatment and the impact of cancer-related infertility. Gynecol Oncol. 2005; doi:10.1016/j.ygyno.2004.12.019

46. Gorman JR, Malcarne VL, Roesch SC, Madlensky L, Pierce JP. Depressive symptoms among young breast cancer survivors: the importance of reproductive concerns. Breast Cancer Res Treat. 2010; doi:10.1007/s10549010-0768-4

47. Ganz PA, Land SR, Geyer CE, Cecchini RS, Costantino JP, Pajon ER et al. Menstrual History and Qualityof-Life Outcomes in Women With Node-Positive Breast Cancer Treated With Adjuvant Therapy on the NSABP B-30 Trial. J Clin Oncol. 2011; doi:10.1200/jco.2010.29.7689

48. Mancini J, Rey D, Preau M, Malavolti L, Moatti JP. Infertility induced by cancer treatment: inappropriate or no information provided to majority of French survivors of cancer. Fertil Steril. 2008;

doi:10.1016/j.fertnstert.2007.08.064

49. Wenzel L, DeAlba I, Habbal R, Kluhsman BC, Fairclough D, Krebs LU et al. Quality of life in long-term cervical cancer survivors. Gynecol Oncol. 2005; doi:10.1016/j.ygyno.2005.01.010

50. Canada AL, Schover LR. The psychosocial impact of interrupted childbearing in long-term female cancer survivors. Psychooncology. 2012; doi:10.1002/pon.1875

51. Meneses K, McNees P, Azuero A, Jukkala A. Evaluation of the Fertility and Cancer Project (FCP) among young breast cancer survivors. Psychooncology. 2010; doi:10.1002/pon.1648

52. Reh AE, Lu L, Weinerman R, Grifo J, Krey L, Noyes N. Treatment outcomes and quality-of-life assessment in a university-based fertility preservation program: Results of a registry of female cancer patients at 2 years. $\mathbf{J}$ Assist Reprod Genet. 2011; doi:10.1007/s10815-011-9559-Z

53. The WHOQOL Group. Development of the World Health Organization WHOQOL-BREF quality of life assessment. Psychol Med. 1998;28(03):551-8.

54. Diener E, Emmons RA, Larsen RJ, Griffin S. The satisfaction with life scale. J Pers Assess. 1985;49(1):71-

5. 
Manuscript Journal of Cancer Survivorship

The final publication is available at Springer via http://dx.doi.org/10.1007/s11764-014-0388-9

55. Brazier J-, Harper R, Jones N, O'cathain A, Thomas K, Usherwood T et al. Validating the SF-36 health survey questionnaire: new outcome measure for primary care. Br Med J. 1992;305(6846):160.

56. Brady MJ, Cella DF, Mo F, Bonomi AE, Tulsky DS, Lloyd SR et al. Reliability and validity of the Functional Assessment of Cancer Therapy-Breast quality-of-life instrument. J Clin Oncol. 1997;15(3):974-86. 57. Brehaut JC, O'Connor AM, Wood TJ, Hack TF, Siminoff L, Gordon E et al. Validation of a decision regret scale. Med Decis Making. 2003; doi: 10.1177/0272989X03256005

58. Zanagnolo V, Sartori E, Trussardi E, Pasinetti B, Maggino T. Preservation of ovarian function, reproductive ability and emotional attitudes in patients with malignant ovarian tumors. Eur J Obstet Gyn R B. 2005; doi:10.1016/j.ejogrb.2005.04.010

59. Huyghe E, Sui D, Odensky E, Schover LR. Needs Assessment Survey to Justify Establishing a Reproductive Health Clinic at a Comprehensive Cancer Center. J Sex Med. 2009; doi:10.1111/j.1743-6109.2008.01005.x 60. Braun M, Hasson-Ohayon I, Perry S, Kaufman B, Uziely B. Motivation for giving birth after breast cancer. Psychooncology. 2005; doi:10.1002/pon.844

61. Patel A, Sreedevi M, Malapati R, Sutaria R, Schoenhage MB, Patel AR et al. Reproductive health assessment for women with cancer: a pilot study. Am J Obstet Gynecol. 2009; doi:10.1016/j.ajog.2009.04.021 62. Atkinson TM, Noce NS, Hay J, Rafferty BT, Brady MS. Illness-Related Distress in Women with Clinically Localized Cutaneous Melanoma. Ann Surg Oncol. 2012; doi:10.1245/s10434-012-2635-5

63. Rippy EE, Karat IF, Kissin MW. Pregnancy after breast cancer: the importance of active counselling and planning. Breast. 2009; doi:10.1016/j.breast.2009.08.003

64. Scanlon M, Blaes A, Geller M, Majhail NS, Lindgren B, Haddad T. Patient Satisfaction with Physician Discussions of Treatment Impact on Fertility. J Cancer. 2012; doi:10.7150/jca.4408

65. Gorman JR, Roesch SC, Parker BA, Madlensky L, Saquib N, Newman VA et al. Physical and mental health correlates of pregnancy following breast cancer. Psychooncology. 2010; doi:10.1002/pon.1614

66. Gershenson DM, Miller AM, Champion VL, Monahan PO, Zhao QQ, Cella D et al. Reproductive and sexual function after platinum-based chemotherapy in long-term ovarian germ cell tumor survivors: A gynecologic oncology group study. J Clin Oncol. 2007; doi:10.1200/jco.2006.08.4590 67. Schover LR, Rybicki LA, Martin BA, Bringelsen KA. Having children after cancer - A pilot survey of survivors' attitudes and experiences. Cancer. 1999; doi:10.1002/(sici)1097-0142(19990815)86:4<697::aidcncr20>3.0.co; $2-\mathrm{j}$ 
Manuscript Journal of Cancer Survivorship

The final publication is available at Springer via http://dx.doi.org/10.1007/s11764-014-0388-9

68. Boss EA, van Golde RJ, Beerendonk CC, Massuger LF. Pregnancy after radical trachelectomy: a real option? Gynecol Oncol. 2005; doi:10.1016/j.ygyno.2005.07.071

69. Jolley JA, Battista L, Wing DA. Management of pregnancy after radical trachelectomy: case reports and systematic review of the literature. Am J Perinatol. 2007; doi: 10.1055/s-2007-986680

70. Leventhal H, Meyer D, Nerenz D. The Common Sense Representation of Illness Danger. In: Rachman S, editor. Contributions to medical psychology. Oxford: Pergamon Pr.; 1980. p. 7-30.

71. Leventhal H, Leventhal EA, Contrada RJ. Self-regulation, health, and behavior: A perceptual-cognitive approach. Psychology \& Health. 1998; doi: 10.1080/08870449808407425

72. Simard S, Thewes B, Humphris G, Dixon M, Hayden C, Mireskandari S et al. Fear of cancer recurrence in adult cancer survivors: a systematic review of quantitative studies. J Cancer Surviv. 2013; doi:10.1007/s11764$013-0272-\mathrm{Z}$

73. Stacey D, Légaré F, Col NF, Bennett CL, Barry MJ, Eden KB et al. Decision aids for people facing health treatment or screening decisions. Cochrane Database Syst Rev. 2014(1). doi:10.1002/14651858.CD001431.pub4

74. Bruera E, Sweeney C, Calder K, Palmer L, Benisch-Tolley S. Patient Preferences Versus Physician Perceptions of Treatment Decisions in Cancer Care. J Clin Oncol. 2001;19(11):2883-5.

75. Degner LF, Sloan JA. Decision making during serious illness: What role do patients really want to play? J Clin Epidemiol. 1992; doi: 10.1016/0895-4356(92)90110-9

76. Degner LF, Kristjanson LJ, Bowman D, et al. Information needs and decisional preferences in women with breast cancer. JAMA. 1997; doi:10.1001/jama.1997.03540420081039

77. Blanchard CG, Labrecque MS, Ruckdeschel JC, Blanchard EB. Information and decision-making preferences of hospitalized adult cancer patients. Soc Sci Med. 1988; doi: 10.1016/0277-9536(88)90343-7 78. Gaston CM, Mitchell G. Information giving and decision-making in patients with advanced cancer: A systematic review. Soc Sci Med. 2005; doi: 10.1016/j.socscimed.2005.04.015

79. Jenkins V, Fallowfield L, Saul J. Information needs of patients with cancer: results from a large study in UK cancer centres. Br J Cancer. 2001; doi: 10.1054/bjoc.2000.1573

80. Mills ME, Sullivan K. The importance of information giving for patients newly diagnosed with cancer: a review of the literature. J Clin Nurs. 1999; doi: 10.1046/j.1365-2702.1999.00296.x

81. Street Jr RL, Makoul G, Arora NK, Epstein RM. How does communication heal? Pathways linking clinician-patient communication to health outcomes. Patient Educ Couns. 2009; doi: 10.1016/j.pec.2008.11.015 
Manuscript Journal of Cancer Survivorship

The final publication is available at Springer via http://dx.doi.org/10.1007/s11764-014-0388-9

82. Gray NJ, Klein JD, Noyce PR, Sesselberg TS, Cantrill JA. Health information-seeking behaviour in adolescence: the place of the internet. Soc Sci Med. 2005; doi: 10.1016/j.socscimed.2004.08.010

83. Rideout V. Generation Rx.com. What are young people really doing online? Mark Health Serv. 2002;22(1):26-30.

84. Bender JL, Jimenez-Marroquin M-C, Jadad AR. Seeking support on facebook: a content analysis of breast cancer groups. J Med Internet Res. 2011; doi: 10.2196/jmir.1560

85. Davison KP, Pennebaker JW, Dickerson SS. Who talks? The social psychology of illness support groups. Am Psychol. 2000; doi: 10.1037/0003-066X.55.2.205

86. Gustafson DH, Wise M, McTavish F, Taylor JO, Wolberg W, Stewart J et al. Development and pilot evaluation of a computer-based support system for women with breast cancer. J Psychosoc Oncol. 1994; doi: 10.1300/J077V11N04_05

87. Gustafson DH, Hawkins R, Pingree S, McTavish F, Arora NK, Mendenhall J et al. Effect of computer support on younger women with breast cancer. J Gen Intern Med. 2001; doi: 10.1046/j.1525-

1497.2001.016007435.x

88. Lieberman MA, Golant M, Giese-Davis J, Winzlenberg A, Benjamin H, Humphreys K et al. Electronic support groups for breast carcinoma. Cancer. 2003; doi: 10.1002/cncr.11145

89. van den Berg SW, Gielissen MF, Ottevanger PB, Prins JB. Rationale of the BREAst cancer e-healTH [BREATH] multicentre randomised controlled trial: an internet-based self-management intervention to foster adjustment after curative breast cancer by decreasing distress and increasing empowerment. BMC Cancer. 2012; doi:10.1186/1471-2407-12-394

90. Winzelberg AJ, Classen C, Alpers GW, Roberts H, Koopman C, Adams RE et al. Evaluation of an internet support group for women with primary breast cancer. Cancer. 2003; doi: 10.1002/cncr.11174

91. Treasure T, Bewley S, Bhattacharya S, Brian K, Child T, Davies M et al. Fertility: Assessment and treatment for people with fertility problems. In: NICE clinical guidelines. National Institute for Health and Care Excellence. 2013. http://publications.nice.org.uk/fertility-cg156/recommendations. Accessed 14 Mar 2014. 92. Quinn GP, Vadaparampil ST, Lee J-H, Jacobsen PB, Bepler G, Lancaster J et al. Physician Referral for Fertility Preservation in Oncology Patients: A National Study of Practice Behaviors. J Clin Oncol. 2009;27(35):5952-7. doi:10.1200/jco.2009.23.0250 
Manuscript Journal of Cancer Survivorship

The final publication is available at Springer via http://dx.doi.org/10.1007/s11764-014-0388-9

93. Peddie VL, Porter MA, Barbour R, Culligan D, MacDonald G, King D et al. Factors affecting decision making about fertility preservation after cancer diagnosis: a qualitative study. BJOG. 2012; doi:10.1111/j.1471 0528.2012.03368.x

94. Dursun P, LeBlanc E, Nogueira MC. Radical vaginal trachelectomy (Dargent's operation): A critical review of the literature. Eur J Surg Oncol. 2007; doi: 10.1016/j.ejso.2006.11.021.

95. Kahneman D, Tversky A. Prospect theory: An analysis of decision under risk. Econometrica. 1979; doi: $10.2307 / 1914185$

96. Treadwell JR, Lenert LA. Health values and prospect theory. Med Decis Making. 1999; doi: 10.1177/0272989X9901900313

97. Blakely LJ, Buzdar AU, Lozada JA, Shullaih SA, Hoy E, Smith TL et al. Effects of pregnancy after treatment for breast carcinoma on survival and risk of recurrence. Cancer. 2004; doi:10.1002/cncr.11929 98. Gelber S, Coates AS, Goldhirsch A, Castiglione-Gertsch M, Marini G, Lindtner J et al. Effect of pregnancy on overall survival after the diagnosis of early-stage breast cancer. J Clin Oncol. 2001;19(6):1671-5.

99. Ives A, Saunders C, Bulsara M, Semmens J. Pregnancy after breast cancer: population based study. Br Med J. 2007; doi:10.1136/bmj.39035.667176.55

100. Fosså SD, Magelssen H, Melve K, Jacobsen AB, Langmark F, Skjærven R. Parenthood in Survivors After Adulthood Cancer and Perinatal Health in Their Offspring: A Preliminary Report. J Natl Cancer Inst Monogr. 2005; doi:10.1093/jncimonographs/lgi019

101. Kenney LB, Nicholson HS, Brasseux C, Mills JL, Robison LL, Zeltzer LK et al. Birth defects in offspring of adult survivors of childhood acute lymphoblastic leukemia: A Childrens Cancer Group/National Institutes of Health report. Cancer. 1996; doi:10.1002/(SICI)1097-0142(19960701)78:1<169::AID-CNCR23>3.0.CO;2-X. 102. Hynie M, Burns LH. Cross-Cultural Issues in Infertility Counseling. In: Covington SN, Hammer BL, editors. Infertility Counseling A Comprehensive Handbook for Clinicians. Cambridge: Cambridge University Press; 2006. p. 61-82. 